\title{
IMPERATIVE IMPLICATIONS OF JOB ANALYSIS ON EMPLOYEES' COMMITMENT OF PUBLIC SECTOR ORGANIZATIONS IN CROSS RIVER STATE, NIGERIA
}

\author{
Ele, Augustine Augustine \\ Department of Business Management, Faculty Of Management Sciences \\ University of Calabar, Calabar- Nigeria, PMB 1115 \\ Email: Elenoble2000@Yahoo.Com \\ Phone No: 07069146713. \\ Makama, Lawrence Linus \\ Department of Business Management, Faculty Of Management Sciences \\ University of Calabar, Calabar- Nigeria \\ Email: Lawrence.Makama@Gmail.Com \\ Phone No: 07069273928. \\ Dr. Okongo, Nsor John \\ Department of Business Management, Faculty Of Management Sciences \\ University of Calabar, Calabar- Nigeria \\ Email: Nsor John@Yahoo.Com \\ Phone No: 08038179681.
}

\begin{abstract}
This research paper centered on the imperative implications of job analysis on organizational performance of public sector organizations in Cross River State. The study adopted a theoretical based approached. Information were sourced from journal articles, text books, internet materials etc. The study revealed that job analysis have a significant influence on organizational performance of the public sector organizations in the state. The study also revealed that job description have a significant influence on employees' commitment of the public sector organization in the State. The study also discovered that job specification and job evaluation also affect employees' commitment of public sector organizations in the State. The study also revealed that job content influence employees' commitment of the public sector organizations and that competency, knowledge, skills, abilities and other job characteristics also influence employees' commitment of the public sector organizations in Cross River State. From the above findings, it was recommended that managers, directors as well as political office holders (politicians) should at all times analyze the jobs and the people who are to do the jobs before recruitment in order to determine their fitness towards the job performance of the public sector organizations in Cross River State. The management should always describe the jobs and its contents before selection for training and recruitment in order to ascertain the focal point of the jobs for effective and efficient organizational performance to be achieved on a continuous basis. The management should also at all times specify the persons and the jobs to be performed in order to determine whether the people have the right qualifications and experience to do the jobs or not, because this would assist to enhance corporate performance of the organizations on a continuous basis. It was conclude that job analysis is a vital tool for effective human resource planning policy of any given organization either private or public. It is a fundamental internal strategy use by human resource managers, job analysts, professionals as well as practitioners in obtaining necessary or pertinent information about the jobs and the workers before or during selection for recruitment as well as training of existing and prospective employees in any given organization. It is also evident that when the people with the right qualifications, experience, competency, knowledge, skills, abilities and other job features are recruited into public sector organizations, its performances will be improved upon steadily in Cross River State.
\end{abstract}

KEY WORDS: job, job analysis, job description, job specification, job evaluation and public sector organizations. 


\section{INTRODUCTION}

For some years now, the imperative implications of job analysis before or during recruitment and selection of the right candidate, for the right job have not been articulated effectively in the public sector organizations of the Cross River State. This can be attributed to the problem of political and legal factors as well as God fatherism of man know man in the society. The prevailing circumstances of poor organizational performance is the absence of job analysis during selection for recruitment and training of existing and prospective employees of the public sector organizations in Cross River State. The public sector organizations in Cross River State have no good human resource planning policy during recruitment and selection, training and development, performance management, succession planning as well as performance appraisal system. This is because job analysis practices such as job description, job specification as well as job evaluation does not exist in the public sector organizations of the Cross River State, for effective and efficient determination for the right persons with the accurate and acceptable knowledge, competency, abilities, skills and other job attributes to be selected during recruitment and training of existing and prospective workers to be made.

Job analysis is the systematic process of studying, identifying, collecting and setting out detail information concerning or relating to the content of jobs in order to provide the fundamental basis for a job description and data for recruitment, training, job evaluation, job specification, career planning, performance appraisal system, promotion and performance management for organizational performance to be accomplished more successfully (Armstrong, 2009; 2012). Job analysis concentrates on what job holders are expected to do and accomplish more successfully. It identifies the tasks job holders undertake and the results as well as outputs they are expected to produce. Job analysis defines the nature, context, content and other characteristics of the job within the organization and the behaviours that necessary associated in performing those jobs.

Job analysis is one of the most important functions or activities of human resource management and can perform multi-functions such as job description, job specification, job evaluation etc. Job analysis can offer a solution for most effective work organization or classification of work, improving ineffective processes of redesign work, planning training for introducing new employees into existing processes, or existing workers in new processes, establishes criteria assessment of employment effect, adequate and fair compensation, advance planning of employees throughout their careers (Stoilkovska \& Serafimovic, 2017). It is an integral part of human resource planning during selection for recruitment and selection for training and development needs assessment.

As human resource activities grow in scope and complexity, many human resource practices such as job analysis, job description, job specification, job evaluation, recruitment and selection, compensation, performance management, career planning, training and development and rewards need to be delegated to the human resource management department. This is because most of the human resource specialists do not know about the details of the jobs and its requirements. Knowledge about the jobs and their requirements that must be collected through a process known as job analysis, in which information about jobs is systematically collected, evaluated and organized. Data about each job and the person who is to perform the job need to be analyzed and gathered in an organization. It is a descriptive process of breaking 
down a specific job into its components by using a collection of tools and techniques to establish job requirements (Rehman, 2009). Job analysis need to be the pillar of recruitment and selection in the public sector organizations (Ashraf, 2017). The content of the jobs as well as the context at which the jobs are to be performed need to be analyzed in order to create effective employees' commitment for organizational performance to be improved upon steadily in the public sector organizations of the Cross River State.

To successfully allocate human resources, it is necessary to develop a strategy for the development of human capital such as job analysis. The fact is that job analysis in the public sector organizations are rarely or never implemented (Stoilkovska \& Serafimovic, 2017). This job analysis document results in three important documents such as job descriptions, job specifications as well as job evaluation that are very vital during or before selection for recruitment and training of workers in any given organization for organizational performance to be enhance steadily. In order for the public sector organizations to have accurate, correct, fair, acceptable as well as reliable recruitment and training of workers, the need for having a professionally completed job analysis is inevitable, specifically when the organizations are large in scope and size (Ali El-Hajji, 2011). Ele, Etebong, Inyang and Eneh (2019) observe that inadequate or lack of a good strategic job analysis before carrying out recruitment and training process has been identified as the major cause of poor corporate performance of the public sector organizations in Cross River State. They further stated that to properly understand the dynamic nature of jobs and its complexities, managers or job analysts must gather necessary information about the jobs and the persons who are to do it from time to time for organizational performance to be enhanced steadily. Job analysis is widely recognized with it uses as organizational data collection technique for the determination of the nature of a job, such as job content, context and requirements with the pertinent technical skills, competencies, knowledge, abilities and other job characteristics needed from employees and the prospective employees to perform their jobs more successfully. Therefore, this paper seeks to examine the imperative implications of job analysis on employees' commitment of public sector organizations in Cross River State.

\section{Statement of the problem}

Public sector organizations in Cross River State have no job analysis programme or practices in their human resource planning policy during recruitment and selection, training and development, performance management, succession planning as well as performance appraisal system. With this, the philosophy of job analysis practices are not systematically established and meticulously followed or outlined when recruiting and training of prospective and existing workers in the organizations, which have created problems for the organizational performance to decrease steadily. The competency, knowledge, skills, abilities and other job characteristics required for the job or jobs are not meticulously describes, specifies and evaluated in order to determine the more qualify and competent candidates to be recruited and trained for the tasks. This is characterized with the problem of lack of job analysis practices in the organizations. Based on the absence of systemically carrying out job analysis results in lack of other human resource practices such as job description, job specification, job evaluation, job design, job security as well as job succession planning, making it difficult to identify the right person for the right job leading to imperfect as well as faulty recruitment and selection in the public sector organizations of the Cross River State. This is because, in recent times, the growing PublicPrivate conglomerates have to inform or sensitize the public sector organizations to concentrate 
on feasible human resource planning policy as well as successively developing best job analysis practices that are generally observed in the private sector. The change and shift from the dominatingly administrative mind set and principles, modern policies as well as practices to systemic job analysis of human resource functions is more of a challenge as it will aid in refining the organizational performance as well as enhancing the productivity in the public sector organizations of Cross River State. Lack of a good strategic job analysis before carrying out recruitment and training process has been identified as the major cause of the poor organizational performance of the public sector organizations in Cross River State.

The issue of analyzing, describing, specifying as well as evaluating the job and its contents towards the persons, who are to perform the work has been disdained or neglected by government during selection for recruitment as well as training of prospective and existing employees of the public sector organizations in Cross River State. The decrease or drawback of the performance of the organizations and the staff commitments is as a result of lack of job analysis practices in the human resource planning processes, that is the derivative function of the government at the period of employment and training of workers in the public sector organizations. A pilot survey has also shown that government ineffectiveness or lack of ability as well as unwillingness of the government to actively or proactively adopt the practice of job analysis in employment, training, promotion, performance appraisal etc., exercises has resulted to a drastic reduction and retardation in the growth and development of organizational performance of the public sector organizations in the state. This can be characterized by political father or God father of man-know-man during employment exercise in the state. This has also affected the workers' commitment as well as employees' performance, since the jobs, its contents and the persons, who are to perform the tasks are not analyze to determine their competency or proficiency, knowledge, skills, abilities and other job characteristics before or during selection for recruitment and training into the public sector organizations of the Cross River State. Therefore, this seminar paper seeks to examine the imperative implications of job analysis on employees' commitment of public sector organizations in Cross River State.

\section{Objectives of the study}

The general objective is to examine the imperative implications of job analysis on employees' commitment of public sector organizations in Cross River State. The following specific objectives were formulated to guide this study:

1. To examine the extent to which job description influence employees' commitment of the public sector organizations in Cross River State.

2. To determine the extent to which job specification affect employees' commitment of the public sector organizations in Cross River State.

3. To assess the extent to which job evaluation affect employees' commitment of the public sector organizations in Cross River State.

4. To examine the extent to which job content influence employees' commitment of the public sector organizations in Cross River State.

\section{Justification for the study}

The study will help managers as well as the administrators to carry out effective and efficient job analysis practices before selection for recruitment and training of existing and prospective workers in order to determine the employees with the right knowledge, competency, skills, abilities and other job characteristics required to do the jobs or works more successfully. The 
study will also aid the management of the public sector organizations in Cross River State, to describe and specifying the jobs and the persons who are to perform the jobs, since the focal points of all organizations either private sector or public sector are the jobs and the people involved in the organizations. This will also assist job analysts in analyzing the jobs and the people who are to perform the tasks perfectly on a continuous basis. It will also help in analyzing the content of the jobs and the context at which the tasks are to be performed.

\section{THEORETICAL FRAMEWORK}

The theoretical framework of this research work was anchored on McCormick Job Analysis modelling and Competency Based Modelling.

\section{McCormick job analysis modelling}

This model was designed by McCormick (1979) in Ele, Etebong, Inyang and Eneh (2019) to describe the basic variables that help in the analysis of jobs to achieve its corporate performance in an organization. McCormick created job descriptors from a model of the operational functions basic to all jobs. This jobs descriptor consists of sensing (information receiving), information storage, information processing, and decision and action (physical control or communication). McCormick (1979) further classified job descriptors as follows: Work activities: these include job-oriented activities and worker-oriented activities. Job-oriented activities focus on the actual activities involved in performing the work. This procedure takes into consideration work duties, responsibilities and functions. The job analyst then develops job statements which will clearly state the jobs that are to be performed with great detail. Worker-oriented procedures aim to examine the human characteristics needed to perform the job successfully (Ele, Eteobong, Inyang \& Eneh, 2019). These human attributes have been commonly classified into four categories such as knowledge, skills, abilities, and other job characteristics.

Other descriptors were machines, tools and equipment needed to perform the job successfully; work performed which involved the actual jobs perform; job context which is the environment at which the job is to be performed; personnel requirements including the type of person needed for the job. This classification suggests that job analysis can yield several kinds of useful job information. These functions may vary in emphasis from job to job that will assist in improving the corporate performance of public sector organizations in Cross River State. This model in this research work will help management and organizations to carry out an efficient job analysis on a continuous basis by taking into consideration the task-oriented procedures and workeroriented procedures in order to improve on its corporate organizational performance steadily. This is to say that both the person who is to perform the job and the tasks must be analyze unlike the traditional method of job analysis, so that, the right people with the right knowledge, skills, competency, abilities and other job characteristics will be selected for recruitment and training in order to enhance the organizational performance of the public sector organizations on a continuous basis in Cross River State.

\section{Competency-Based Modelling}

Competency-based modelling in human resource management is about utilizing competency and results of competency analysis to inform and improve human resource processes, especially those concerned with recruitment and selection, training and development, 
performance management and reward management (Armstrong, 2012; Ele, Etebong, Inyang \& Eneh, 2019)). It have an essential part to play in job analysis practices or activities. Competency refers to an employee's behaviour and its applications in regard to knowledge. Competency is the underlying characteristic of a person that results in effective or superior performance (Armstrong, 2012). The core competency is the organizations collective learning, especially the capability to coordinate and control the different production skills and the integration of these skills into what they called streams of technology (Weihrich \& Koontz, 2005).

Competency models account for those intangibles, skills, and attitudes which meet the needs of the organization that the traditional job analysis is no longer able to do (Bodner, 1999). However, competency-based modelling is primarily based on the concepts of behavioural and technical competencies to achieve expected corporate performance in an organization. Behavioural competencies define behavioural expectations which are the type of behaviour required to deliver results under such headings as team work, communication, leadership and decision making. Technical competencies define what people in organization have to know and able to do with adequate knowledge and skills to carry out their jobs more effectively. They are sometimes known as soft and hard skills (Armstrong, 2009). Competency assessment offers the opportunity for organizations to develop competencies by position and to generate interview guidelines that are more likely than traditional models to help the employer recruit the best person for the job and the organization (Meade, 1998). Competency assessment is increasingly being using as the basis for initiating, developing, and guiding both training and development and recruitment and selection. Competency which refers to the knowledge, skill, attitude or characteristics associated with high performance is essentially needed in these modern firms. Nolan (1998) specified the methods or steps in determining competencies, but there is much more in developing a competency model that identifies the competencies. These steps are as follows: Specify the role and work setting; Identify competency areas; Write competency statements; Write performance criteria; Develop competency assessment tools; Design a documentation method for proper implementation to be achieved.

The concept of competency is essentially about performance. Organizations are looking for new ways to integrate job analysis practices in all areas of the organization to achieve corporate performance. Most especially the public sector organizations that have not realized this dream in competency assessment and they need to implement it throughout the organizations through job analysis on whom is to be recruited and to be trained for corporate organizational performance to be achieved efficiently (Mclangan, 1997; Bodner, 1999). Competency-based models provide valuable information, and they are all useful when there is a coherent and systematic implementation strategy to leverage the essential information obtained through a job analysis programmes before or during selection for recruitment and training of existing and prospective workers (Ele, Eteobong, Inyang \& Eneh, 2019). Competency-based modelling involve the systematic evaluation of the capacity, knowledge, skills, abilities and other job characteristics required from job holders to perform tasks and duties more effectively in order to enhance corporate performance. The value of this model is for the management to analyze the person to be recruited and to be trained based on the competencies, abilities, skills, knowledge, and other job characteristics needed to perform the jobs in an organization more effectively. And when you are talking about competencies, you are emphasizing about improved performance to be made on a continuous basis. 
International Journal of Business and Management Review

Vol.8, No.1, pp.49-68, January 2020

Published by ECRTD-UK

Print ISSN: 2052-6393(Print), Online ISSN: 2052-6407(Online)

\section{LITERATURE REVIEW}

\section{The concept of job analysis and organizational performance}

Job analysis is an organized study of jobs to recognize the visible work activities, tasks, and responsibilities related with a particular job or cluster of jobs. It is a process of looking at exactly what a job entails and to identify the particular job duties and requirements in detail reflecting the importance of these duties for a given job. The significance of job analysis in applying human resource practices cannot be ignored, as job analysis has been described as the fundamental building block upon which all later decisions in the process would rest upon. Job analysis is a process of comprehensively studying the job or task to determine what it entails (Rehman, 2009). Job analysis is one of the most important activities of human resource management and can perform multi-functions. A regular or proactive job analysis practices help to identify factors that shape the employees motivation and job satisfaction (Suthar, Chakwrawathi \& Pradhan, 2014). Job analysis is a process in which the entity as well as features of each job in organization is investigated, sufficient information about them is collected and reported. With job analysis, its specified jobs consists of what duties and what skills as well as knowledge are required to carry out the task appropriately (Mozdabadi, 2017).

The strong impact of job analysis on several measures of performance suggests that job analysis is indeed a cornerstone of HR activities and a vital strategic management practice to gain competitive advantage. Job analysis increased simply to answer two basic questions, what tasks to be performed and what information is needed to enable the work to be done (Nyasha, Katsuro, Chazuza, Makaita, Mukondiwashe, Tafadzwa \& Taonga, 2013). They further stated that a well-established job analysis has positive implications on employees, organizational performance, labour turnover, growth, market share and market value of bread manufacturing companies.

Job analysis is an organized assessment, study and recording the responsibilities, duties, skills, accountabilities, work environment and ability requirements of a specific job. It also involves determining the relative importance of the duties, responsibilities and physical and emotional skills for a given job (Ashraf, 2017). He further added that job analysis leads to identification of the personal requirements imperative to perform the required job such as aptitudes, physical characteristics, personality, and most importantly job-related knowledge and skills. Job analysis aided managers with feasible techniques and tools towards recruitment and selection of prospective workers and when decisions are taken during performance appraisal, promotion, performance management, training and development and other related decisions of human resource planning practices (Kshatriya, 2016). He further stated that job analysis answers the questions of what tasks to be performed and in what means to make up the job utilizing performance management systemic technique. Managers that incorporate job analysis through the work prescription discipline and compliance to aid in planning and controlling human resources. Job analysis is a formal written expression of the plans for a specific future period stated in job description terms. Tools for business decision making lists the following benefits of job analysis: It requires all levels of management to plan ahead and formalize goals on a repetitive basis. It provides definite objectives for evaluating performance at each level of responsibility. It creates an early warning system for potential problems so that management can make changes before things get out of hand. It facilitates the coordination of activities within the company by correlating segment/division goals with overall company goals. It 
results in greater management awareness of the company's overall operations including the impact of external factors such as economic trends. It motivates personnel throughout the company to meet planned objectives. Absence of job analysis implementation is a key factor to many organizational gaps since it facilitates and lays the foundation of countable needed practices (Ashraf, 2017). Job analysis can be considered as a cornerstone in the job evaluation process, and evaluation is an essential usage to job analysis (Ali El-Hajji, 2011). He further stated that differential wages can be paid to jobs of different worth. Job analysis is the basic and important part of human resource management. This indicates what activities and accountabilities the job entails. It is an accurate recording of the activities involved. Every job is multi-faceted and there are several methods in preparing job analysis such as questionnaires, interviews observation, etc. (Saif, Khan, Rehman, Shafiq-ur, Zia-Ur, Nawa \& Naqeeb, 2013). Job analysis is a device use to identify similarities and dissimilarities among the jobs assigned to tasks and the responsibilities in a working organization for gathering of data and evaluating information from which job description, job specification, job evaluation and job performance standards are generated or developed. The basic products of job analysis are job description, job specification and job evaluation.

Job analysis is the systematic process of collecting relevant, work-related information as to the nature, scope and responsibilities of jobs. As the result of job analysis will helps people and the organization to gain a greater understanding of and be able to document the knowledge, skills, abilities and others factors/characteristics required to successfully perform a job. Job analysis is the foundation upon which job descriptions are written and defines job content. From this, is the reason while job analysis was viewed as the hub of virtually all human resource management activities or practices that are necessary for the successful functioning of organizations (Singh, 2008; Siddique, 2004; Oswald, 2003). Specifically, the field of job analysis will benefit public sector organizations by paying a closer attention to the strategic and future oriented needs of organizations (Singh, 2008). Job analysis has actually grown considerably in scope and applications, especially over the last few decades. Job analysis is a vital and rich source of information about jobs and jobholders that human resource professionals/managers use to develop such essential documents as job description, job specification and performance standards in order to increase corporate performance. These documents served as basis of human resource management decisions in a number of interrelated areas. Thus, human resource practices such as training and development, recruitment and selection strategies, performance appraisal, compensation, health and safety requirements are increasingly developed around the demand and characteristics of jobs. The effectiveness of these human resources activities needs that jobs must be clearly understood both the jobholders and the organization. Therefore, the practice of job analysis provides this understanding (Siddique, 2004).

\section{Job description and organizational performance}

Job Description is a written statement that describes the duties of a jobholder, how the duties should be done and why it is done. Typically, job description described the job content, environment, context, nature, and conditions of employment. The focal point of job description is the job. Job description document are the most essential features of a job, including a description of the important functions of the job that details the required knowledge, skills, abilities, responsibilities and reporting structure. The mental and physical requirements of the jobs are also included that are typically required to perform the essential functions of the job 
for disability act consideration (HR Guide, 2012). Al-Marwai and Subramaniam (2009) stress that job description is a document that serves very many essential functions in organizations, if written properly and constantly updated, it provides the employees with structure and design they need to carry out their jobs. Gan and Kleiner (2005) state that if job descriptions when effectively formulated and implemented, are capable of affording the organizations with the following useful objectives such as assisting in planning for the future; being able to measure future performance; enhancement of communication between employer and employees; enhancing the skills and abilities to retain qualify employees; and setting the criteria for the fair and legal discipline or terminating the workers that are unable to meet their expectations.

What is important here is the updating of job descriptions and the writing of new job descriptions that bring about a number of strategic benefits to the organizations that utilized effective mechanisms to ensure that job descriptions are continuously updated and new ones are written where needed (Al-Marwai \& Subramaniam, 2009). However, job descriptions are building blocks for enterprise wide talent management systems such as training, coaching, recruitment, performance assessment, succession planning, and job-competency modelling (Stybel, 2010). Job descriptions are based on objective information obtained through job analysis, an understanding of the competencies and skills required to accomplish needed tasks, and the needs of the organization to produce work (Singh, 2010). The best job descriptions are living, breathing documents that are updated as responsibilities and duties change. The best job description do limits employees, but rather cause them to stretch their experience, grow their skills, and develop their abilities to contribute greatly within their organizations (Singh, 2010). Job description is an organized factual statement of the duties and responsibilities of a specific job. Job description in nature constitutes a record of existing and pertinent job facts, (Inyang \& Akpama, 2002). Job description is the broad outline of what tasks a job consists of by delineating its duties and responsibilities and the position of the job within the organization to improve performance. It can also be seen as a pertinent facts statement relating to all the technical, administrative and managerial aspects of the job, the job title, job summary, job duties, tasks and outputs that will helps to improve the corporate performance of the organizations.

Good design structure creates job description, job specialization and performance standard that will motivate the employees and lead to their performance. These aspects of the jobs are found in job analysis, because job analysis is a process of determining the tasks that makes up the job and skills, abilities and responsibilities required for the job holder (Raju \& Banerjee, 2017). During recruitment and selection as well as training, job description is require to be frequently checked and reviewed in the light of on-going changes and the related concepts that influence the job content, job demands and job requirements (Ali El-Hajji, 2011). This is necessary in order to re-determine the rating of the job worth, job relativities and the work was only describe and not the worker. Job description has many uses such as recruitment and selection, training and development needs, performance appraisal and other organizational goals and activities. Job description is an output of job analysis, while job analysis is an input for job evaluation (Ali El-Hajji, 2011). This is because the quality and soundness of job description reflects the quality and soundness of job analysis. Job description embraces the physical and mental characteristics needed for the job, the personal achievements considered necessary for and specific to the job, the full range of vertical and horizontal communication channels that need 
to be maintained on reciprocal basis, the job environmental circumstances or working conditions, the necessary materials and equipment required for the job.

\section{Job specification and organizational performance}

Job specification or man specification or employee specification is the list of the essential components of a job including a summary of the work to be performed, primary duties and responsibilities, and the minimum qualifications and requirements necessary to do the crucial works of the job (Sharif \& Karim, 2017). Job specification is an organized factual statement of a specific job which tells us the minimum acceptable human qualities which helps to perform a job. Job specification translates the job description into human qualifications so that a job can be performed in a better manner. This is a standard of personnel and designates the quality required for acceptable performance (Inyang \& Akpama, 2002). Job specification deals with the personal aspects of the job and education or qualification background, skills, knowledge, ability and other job characteristics required to do the job (Edien, 2015). Thus, job specification also involves knowledge, skills, abilities and other characteristics needed to perform the jobs. Amos, Ristow and Ristow (2004) define job specification as a statement that deal with the personal aspects of the job and the educational qualifications background, skills, knowledge, abilities and experience to perform a job. It is a written record of the requirements sought in an individual worker for a given job (Singh, 2010). It is prepared on the basis of job description. It specifies the qualities required in a job incumbent for the effective performance of the job (Singh, 2010). Job specification is a very vital tool during the employees' recruitment, training and development process and provides business owners and managers in respect of the skills, education, work experience, managerial experience, and other human assets or capital which may be required from applicants to perform a particular job within the organization. However, job specification is the systematic process of specifying the type and calibre of person that is considered fit for a particular job. In other words, job specification shows the minimum acceptable qualifications the person should possessed in order to be fitted or capable in performing a particular job more effectively. The focal point in job specification is the person.

\section{Job evaluation and organizational performance}

Job evaluation is the vital foundation upon which the structure of wages and salaries rest. Wages and salary structures are essential instrument developed to translate as well as reflect the organization's remuneration policy into a formal hierarchy of given grades and levels of workers (Ali El-Hajji, 2011). Job evaluation is the systematic examination or determination of the relative worth of jobs within the organization and is concerned with the value of a job to the organization. Cole (2002) describe job evaluation as the name given to any activity which sets out to make a systematic comparison between jobs to assess their relative worth, for the purpose of establishing a rational pay structure. Job evaluation aims to assess the relative worth of a given collection of duties and responsibilities to the organization, which helps the management to maintain high levels of employees as well as employees' satisfaction (Singh, 2010). Cole (2002) further stated that job evaluation aims to reduce reliance on arbitrary methods of pay determination by introducing an element of objectivity in the ways jobs are compared with one another. Job evaluation is an open document available for checking, reviewing and appealing its results if needed for current future development (El-Hajji, 2011). Similarly, the job evaluation process determined the relative worth of each job by establishing a hierarchy of positions within an organization. Job evaluations are typically completed after the job analysis and job description in collaboration with the job specification exercises are 
completed. The job evaluation can be either a non-quantitative method such as job classification, or a quantitative method such as a job point factor process which utilizes compensable factors to include skill, responsibility, effort, working conditions and supervision of others to determine internal worth. Job evaluation is a key for developing an internally consistent compensation system as a strategic tool for an organization to improve its corporate organizational performance.

\section{Job content and organizational performance}

Job content here describes the essential functions and is a vital tool that will enable people/employees to price jobs in the market and ensure improved compliance with various employment related laws. Job content is the major components or ingredients that are involve in a particular task or responsibility. Changes in society, business and technology that can be expected due to job analysis will be the new challenges to supply the kinds of information needed to ensure the success of future human resource planning. However, there will also be new possibilities for producing, analyzing, and updating information due largely to changes in technology, recruitment and selection of existing as well as prospective employees of the public sector organizations in Cross River State. It can be considered that likely developments in job analysis with regard to descriptors or types of data, the sources of information, data collection methods, and the units of analysis and introduction of methods for data storage, retrieval and dissemination are needed in analyzing a job content as well as job context for performance efficiency to be enhanced steadily. Amos, Ristow and Ristow (2004) in Rehman (2009) stated that both the content and context of the job should serve as the basis for recruiting and selecting the most suitable candidate for the job. Both, job description and job specification have a significant role in the selection process and the identification of the best possible match for a position.

It has been observed that the administrative and managerial proficiency of the public sector employees has been declining. Human resource planning (HRP) in the public sector has not been given adequate significance which led to steady destruction in capability and managerial skills of the public sector employees. Public sector organizations rely on the professionals employed locally of from overseas even for normal strategy formulation as well as its implementation, and their output is generally not efficiently being utilized due to their lack of ability to understand the content and context of the jobs (Ashraf, 2017). Job succession planning depends upon performance evaluation reports quantification, job experience, promotion quota, seniority cum fitness and in some cases fitness cum seniority. The rationale for the public sector reforms was to develop and to be effective or efficient in order to ensure the sustainability and survival of the organizations' performance at regular interval. The ultimate objective is to acquire improved structure which the general public believe that is essential to move forwards the organized potential in the public sector organizations to perform the main government functions. The core intentions were to produce a competent, knowledgeable, skill as well as specialized civil service administration that is sensitive to the requirements of the organizations in changeable socio-economic setting and zealous to become contented with change or transformation using innovative job analysis practices and motivated employees with the right competent, knowledge, skills, abilities and other job characteristics to perform the global as well as national tasks. 


\section{Recruitment and selection and employee' commitment}

As there is increase in the recruitment and selection of the right person for the right job, at the right time posts a challenge on the corporate employees' performance of public sector organizations. Employees' recruitment and selection activities are quite an investment most especially in the private sector organizations. Recruitment and selection involve getting the best applicant for job. For more efficient and effective recruitment processes are needed to identify the right person for the positions of directors/mangers as a result of their direct impact on stakeholders and the. In the drive to succeed and achieve effective corporate performance, organizations need to make sure that the right people are being selected to accomplish the right job. Amos, Ristow and Ristow (2004) state that selection was the process of identifying the most suitable and qualified applicant to perform a specific job from a pool of applicants obtained in the recruitment phase. It is in essence a matching exercise whereby an organization sets out to find the best possible match of person to a job. Recruiting employees is of key importance to the overall productivity of organization most especially the private sector organizations. Recruitment involves the process of an organization attempting to engage additional human resources for operational purpose to enhance the objectives of the firm (Inyang \& Akpama, 2002). They further stressed that a wrong selection procedure will mean a heavy loss to an organization in terms of expenditure incurred in selection, induction, training and subsequent poor performance of both the employee and the organizations. If organizations are able to find and employ employees that are consistently fulfilling their roles and are capable of taking on increased responsibility, they are immeasurably better placed to deal with the opportunities and threats arising from their operating environment those competitors who are always struggling to build and maintain their workforce. The success or failure of an organization largely depends upon the calibre and positive quality types of the people recruited and work there in. An organization can improved its organizational performance, progress and prosper with an increasing growth and development only with the useful creative contributions from its employees.

Job analysis determines the knowledge, skills, abilities and other job characteristics (KSAOCs) vital and required for each position. Job analysis sets the qualifications required for a job including minimum education, certification, or licensing. The fundamental responsibilities of the job are also determined by job analysis. This information is processed by the organizations and further used to hire and recruit future employees. Job analysis plays a crucial part during the pre-employment examinations for selection and promotion. The examinations held must associated with the job. The characteristics for which the people are tested for include knowledge, skill, different abilities, and character (personality) variables. An organization only discovers what knowledge, skills, and abilities to test for when it knows what competencies are required to execute a job successfully (Ashraf, 2017). Job analysis is a key to recruitment, selection, orientation, training, career development, counseling, health, safety, performance management as well as compensation (Kshatriya, 2016). This implies that a strategic job analysis need to be carried out in the public sector organizations for effective and efficient recruitment and training process in order to improve its employees' commitment as well as organizational corporate performance. The purpose of a recruitment function include seeking out, evaluating, obtaining commitment from place and orientating new employees to fill positions required for the successful conduct of the work of an organization. Business enterprises in the private sector organizations enter into this activity (job analysis) currently to 
International Journal of Business and Management Review

Vol.8, No.1, pp.49-68, January 2020

Published by ECRTD-UK

Print ISSN: 2052-6393(Print), Online ISSN: 2052-6407(Online)

add, to maintained or re-adjust their total human resources complement in accordance with business requirements to improve its corporate performance.

\section{Applications of job analysis}

According to Singh (2010); HR Guide (2012) and Wikipedia (2019) the applications of job analysis can be summarized below:

Applications of job analysis begins with the determination of training needs which is a vital tool for training needs assessment to establish and identify the training content, assessment tests to measure the effectiveness of training equipment to be utilized in delivering the training, methods of training such as on-the-job, off-the-job, vestibule, apprenticeship, classroom, small group and computer-based, etc. to enhance the corporate performance as well as employees' commitment of public sector organizations. Job analysis can also be used in predicting human resource planning requirement in terms of technical knowledge, skills, abilities and other job characteristics required to perform the jobs in an organization. Job analysis can be used to determine compensable job factors, skill levels, work environment such as (attention, hazards, physical effort), responsibilities, required level of education directly or indirectly related to salary level. Job analysis also helps human resource professionals to take a bold step further in developing a recruitment plan that will assist to match the job requirements with the workers knowledge, attitudes, skills, abilities and interest for effective performance to be enhanced. Through job analysis the job incumbent or management will have deep understanding of the job which gives the basic tenet to select the right person at the right time for the right job. Job analysis can also be used in performance appraisal or review for the determination and development of goals and objectives, performance evaluation criteria, length of probationary periods, and duties to be evaluated.

Other applications of job analysis include placement and orientation because having selected the best applicants; they have to be placed on the right jobs best suitable to their interests, activities and aptitudes. Thus, an effective job orientation can be achieved with adequate understanding of the needs of each job. Therefore, to teach a new employee how to handle a job, managers have to clearly analyze the job that is to be performed. Human resource managers can adequately counsel employees about their areas when they understanding different jobs in an organization. The job evaluation process determines the relative worth of each job by establishing a hierarchy of positions within an organization. The concept of job analysis also helps to group jobs into classes and families. This simplifies the overview for human resource managers and is essential for streamlined functioning of an organization. This is common among the private sector organizations in Nigeria. Through job analysis exercise job succession planning is a positive effort to ensure that top management and human resource professionals in an organization would be identifying how the vacant positions would be filled if an employee quit his or her job.

\section{Empirical reviews}

Ashraf (2017) conducted a study by examining the public sector recruitment and selection in relation to job analysis in Pakistan. Questionnaires and some brief interviews was used by adopting 5 points Likert scale. Unstructured interviews was also adopted. Primary and secondary data was collected for the study. Descriptive research design was adopted for the research work. The study revealed that the hiring process of public sector faulty mainly because 
of poor job analysis. They do not make proper job description and specification and employees tasks do not match with the given job description as well as specification, which ultimately affects the performance of the public sector organizations.

Sharif and Karim (2017) also conducted a study on the influence of job analysis programme on employees' performance: a study of selected companies of Bangladesh. The research work adopted an exploratory research design. Primary data was gathered through structured questionnaire. Secondary sources were also adopted. The study revealed that the concept of job analysis is not a popular one in their local organizations. And that the programme helped participants to identify job duties and responsibilities properly, making them aware of their career development. The job analysis process must be continuously evaluated through feedback mechanisms like employee adaptation and performance. Training program should be arranged from time to time. That a list of clear duties and responsibilities must be specified according to position of employees. That improvement of employee skill is highly required in the companies. Organizational arrangement of skill improvement programmes is required.

Suthar, Chakravarthi and Pradhan (2014) conducted a study on impacts of job analysis on organizational performance: an inquiry on Indian Public Sector enterprises. The study used survey questionnaire to gathered data. The questionnaire was administered through email to the respondents. The population was one thousand, three hundred and sixty one. The sample size was four hundred and seventeen. The study adopted quantitative research approach. Regression and correlational models were used to test the hypotheses. The study indicated that organizational performance and job analysis are positively related with each other. The study also revealed that there is a significance relationship between organizational performance and job design; organizational performance and job specification as well as organizational performance and job evaluation. The study recommended that management should conduct job analysis activities in a more scientific way that can provide specific direction to use available human power at appropriate time and place. Management should also focus on modern job description as well as job specification activities by considering the factors such as organizational goal- oriented functions and responsibilities, transparent job performance standards as well as free from undue influence and factors such as transparent job specification criteria (emotional specification, social specifications, behavioural specifications).

Nyasha, Katsuro, Chazuza, Makaita, Mukondiwa, Farai, Kudakwashe, Tafadzwa and Taongo (2013) conducted a study on the importance of establishing a job analysis exercise in an organization: a case of bread manufacturing companies in Zimbabwe. Interviews and questionnaires were used in triangulation to collect data from the sample. 5 points likert scale was adopted in the structured questionnaire. The population was 7 companies. The population was divided into strata. The sample size was 4 companies and ten percent of each group was selected using random sampling technique. The data collected was presented using simple percentages. The study found that there is a positive correlation between well-established job analysis and employee and company performance, the impact was seen through improvements in compensation, training and development, health and safety and recruitment and selection. The research work also found that in an era of continuous delayering and downsizing one of the most common problems derived from implementing a job analysis is employee fears. Employees see job analysis as a threat to their current jobs or pay levels or both. This was based 
on the fact that in the past, job analysis was used as a means of expanding jobs while reducing the total number of employees.

Mozdabadi, (2017) also conducted a study on investigation of educational needs with job analysis approach (case study: financial and urban economy experts of Tehran Municipality). The population of the study was one hundred and forty three. The sample size was also one hundred and forty three, and purposive sampling was used. Data were collected using semistructured questionnaire and interview. Mixed exploratory research design was adopted. The Lee Hee and one sample T-tests was used to test hypotheses. The study revealed that since experimental means are higher than theoretical ones, it can be stated that all obtained skills, knowledge, tool, and technology related to Tehran Municipality's urban economy experts are significantly higher than average in terms of total of the three components of learning necessity, frequency, and learning difficulty and they are counted as educational need. The study recommended that in order to increase educational effectiveness, detected priorities for financial and urban economy experts should be put on agenda by educational managers of Tehran Municipality through job analysis practices. It was also recommended that educational managers of Tehran Municipality should try to increase effectiveness of holding these courses.

Kshatriya (2016) also conducted a study on job analysis and its positive impact on key recruitment and selection processes as a case study. Structured questionnaire was used. Simple random sampling was adopted. The study adopted functional job analysis methodology that were job duties as well as job specifications were initially identified as key knowledge, skills, abilities and other job characteristics required for the job were extracted from critical statements using task statements and task inventory as a job classification requisite position. A performance appraisal technique was developed based on an absolute rating system using graphical rating scale aligned to the KSAO's derived from job analysis.

Musyoka, Adoya and Ongombe (2016) carried out a study on the influence of job description on performance of health workers in public Hospitals: A case of Mbagathi Hospital Nairobi city country. The study adopted cross sectional descriptive and exploratory research. The sample size of one hundred and seventy seven respondents was determined using Taro Yamane (1967). Stratified sampling was used. Informant interviews and structured questionnaires were also used. Quantitative and qualitative data was analyzed using descriptive statistics and content analysis respectively. The statistical tool adopted to test for the hypotheses was chisquare using SPSS version 21. The quantitative data collected was coded, processed and present inconsistencies and outliers. Results indicated that the health service managers were not aware of policies on human resource management practices such as job analysis, job description as well as job specification. The study also revealed that there was no significant association between the use of job description dimensions and performance dimensions. Work plans were lowly used and in some cases not available. The study concludes that human resource management practices were poorly implemented in the hospital. Health service managers needed basic training on job description among other HRM practices including and to establish a department that will implement the practices.

\section{Implications of the study}

Effective recruitment and training of existing workers as well as prospective employees is vital to enhance the job performance and productivity of an organization through proper job analysis 
exercise which is an important function of human resource practices. This valuable information of job analysis will contribute to the knowledge of the researchers as well as provide much needed information to the human resource managers. The outcomes of the present study would be of great assistant to the human resource professionals and top-management as they search for ways to increase the productivity and reduce the turnover through job satisfaction of their employees. Observing and documenting the factors which influence job performance of an employee will form a data bank of information that will be useful to HR managers / recruiters. Knowledge of such information will facilitate a better method of human resource planning by the management and can be given to HR professionals for integration of HRM into the business strategies. Policy-makers can also benefit in developing budgets and long term plans for their respective organizations. An understanding to assess the key success factors of a job insight (in the light of knowledge, skills, competency and abilities) self-insight possessed by an employee will increase our knowledge of behaviour in the job performance and contribute to the HR literature. Indeed, this study will help to defines how job analysis will flows in the public sector organizations. In the age where employment generation is a necessity, public sector organizations are faced with challenges to hire the best among the candidates or aspirants. Basically, job analysis will provides public sector organizations an avenue to relate its organizational needs with the prospects. Although, most of the public sector organizations have developed quality recruitment processes but the effects of such procedures are rare. It will help when job analysis is incorporated in the process of recruitment.

\section{DISCUSSION OF FINDINGS}

The study revealed that job analysis have a significant influence on organizational performance of the public sector organizations in Cross River State. This result was supported by assertion of Suthar Chakravarthi and Pradhan (2014) which stated that job analysis has a positive and significant impact on organizational performance of the Indian Public Sector enterprises. The study also revealed that there is a significance relationship between organizational performance and job design; organizational performance and job specification as well as organizational performance and job evaluation. The result is also supported with the assertion of Nyasha, Katsuro, Chazuza, Makaita, Mukondiwa, Farai, Kudakwashe, Tafadzwa and Taongo (2013) which stated that there is a positive correlation between well-established job analysis and employee and company performance, the impact was seen through improvements in compensation, training and development, health and safety and recruitment and selection. Kshatriya (2016) also revealed that job analysis has a positive impact on key recruitment and selection processes which help in enhancing organizational performance at regular interval.

The study revealed that job description have a significant influence on employees' commitment of the public sector organizations in Cross River State. Ashraf (2017) revealed that the hiring process of public sector organizations are faulty mainly because of poor job analysis. He further explained that they do not make proper job description and specification and employees tasks do not match with the given job description as well as specification, which ultimately affects the performance of the public sector organizations. Ele, Etebong, Inyang and Eneh (2019) also assert that effective and efficient job description has a significant and positive effect with the corporate performance of some selected private sector organizations in Cross River State. Musyoka, Adoya and Ongombe (2016) also asserted that public health service managers 
needed basic training on job description among other HRM practices inclusive in order to establish a department that will implement the practices of job analysis

The study also discovered that job specification significantly affect employees' commitment of the public sector organizations in Cross River State. The finding was supported by the assertion of Ele, Etebong, Inyang and Eneh (2019) which stated that effective job specification do significantly influence the corporate performance of the selected private sector organizations in Cross River State.

The study also revealed that job evaluation also affect employees' commitment of the public sector organizations in Cross River State. Singh (2010) asserts that job analysis can be used to determine compensable job factors, skill levels, work environment such as (attention, hazards, physical effort), responsibilities, required level of education directly or indirectly related to salary level. He further stated that job evaluation process determines the relative worth of each job by establishing a hierarchy of positions within an organization.

The study also revealed that job content influence employees' commitment of the public sector organizations in Cross River State. The result was also supported by findings of Nyasha, Katsuro, Chazuza, Makaita, Mukondiwa, Farai, Kudakwashe, Tafadzwa and Taongo (2013) which found that in an era of continuous delayering and downsizing one of the most common problems derived from implementing a job analysis is employee fears. Employees see job analysis as a threat to their current jobs or pay levels or both. This was based on the fact that in the past, job analysis was used as a means of expanding jobs while reducing the total number of employees.

The research work also revealed that competency, knowledge, skills, abilities and other job characteristics also influence employees' commitment of the public sector organizations in Cross River State. This result is supported by finding of Ele, Etebong, Inyang and Eneh (2019) which found that competency, knowledge, skills, abilities, and other job characteristics needed from workers or employees to do the jobs more successfully can affect or do significantly lead to an effective increased in the productivity of the selected private sector organizations as well as public sector organizations in Cross River State. They further stated that inadequate or lack of a good strategic job analysis before carrying out recruitment and training process has been identified as the major cause of poor corporate performance of the public sector organizations in Cross River State

\section{CONCLUSION}

Job analysis is a vital tool for effective human resource planning policy of any given organization either private or public. It is a fundamental internal strategy use by human resource managers, job analysts, professionals as well as practitioners in obtaining necessary or pertinent information about the jobs and the workers before or during selection for recruitment as well as training of existing and prospective employees in any given organization. And this will help in the strategic determination of organizational performance on a continuous basis. Job analysis has a significant effect on the growth and development of organizational performance of the public sector organizations in Cross River State. Job description as well as job specification also has a significant influence on organizational performance by determining 
the right person with the right competency, knowledge, skills, abilities and other job attributes to do the jobs more effectively. Job evaluation also affect employees' commitment of the public sector organizations in Cross River State. Analysis of the job content as well as the job context affects employees' commitment positively in enhancing the corporate organizational performance of the public sector organizations in Cross River State. From the above, it is evident that when the people with the right qualifications, experience, competency, knowledge, skills, abilities and other job features are recruited into the public sector organizations, its performances will be improved upon steadily in Cross River State.

\section{Recommendations}

Based on the findings, the following recommendations were made:

1. Managers, directors as well as political office holders (politicians) should at all times analyze the jobs and the people who are to do the jobs before recruitment in order to determine their fitness towards the job performance of public sector organizations in Cross River State.

2. The management of public sector organizations in Cross River State, should always describe the jobs and its contents before selection for training and recruitment in order to ascertain the focal point of the jobs for effective and efficient organizational performance to be achieved on a continuous basis.

3. The management of public sector organizations in Cross River State, should also at all times specify the persons and the jobs to be performed in order to determine whether the people have the right qualifications and experience to do the jobs or not, because this would assist to enhance corporate performance of the organizations on a continuous basis.

4. The management should also evaluate the worth of the jobs and its contents during recruitment process in order to enhance employees' commitment in the job performance of public sector organizations in Cross River State, by determining the competency, knowledge, abilities, skills and other job characteristics for the jobs.

5. The management should also evaluate the prospective employees before selection for employment and selection for training of existing and prospective workers in order to enhance organizational performance of public sector organizations in Cross River State steadily.

\section{REFERENCES}

Ali El-Hajji, M. (2011). Some recent trends in writing job description for the purpose of job evaluation: A reflective view. American International Journal of Contemporary Research, 1(3), 6-14.

Al-Marwai, S. A. \& Subramaniam. I. D. (2009). A review of the need for writing \& updating job descriptions for $21^{\text {st }}$ century organizations. European Journal of Social Sciences, 12(2), 241-251.

Amos, T., Ristow, A. \& Ristow, L. (2004). Human resource management ( $2^{\text {nd }}$ ed). Lansdowne: Juta Publisher.

Armstrong, M. (2009). Handbook of human resource management practice (11 ${ }^{\text {th }}$ d). India: Replika Press Pvt Limited.

Armstrong, M. (2012). Handbook of human resource management practice $\left(12^{\text {th }} \mathrm{ed}\right)$. United Kingdom: Ashford Colour Press. 
International Journal of Business and Management Review

Vol.8, No.1, pp.49-68, January 2020

Published by ECRTD-UK

Print ISSN: 2052-6393(Print), Online ISSN: 2052-6407(Online)

Ashraf, J. (2017). Examining the public sector recruitment and selection, in relation to job analysis in Pakistan. Cogent Social Sciences, 3, 1-11.

Bodner, S. L. (1999). The evolution of job analysis: Competency assessment comes of age. International Journal of Career Management, 7(6), 3-9.

Cole, A. (2002). Personnel and human resource management (5ed). London: Book Power/ELST Imprint.

Edien, A. G. A. (2015). Effects of job analysis on personnel innovation. International Journal of Business and Management Invention, 4(10), 9-18.

Ele, A. A., Etebong, A. U., Inyang, B. J. \& Eneh, S. I. (2019). Effect of job analysis on corporate performance of the selected private sector organizations in Cross River State, Nigeria. IOSR Journal of Business and Management (IOSR-JBM), 21(11), 41-52.

Gan, M. \& Kleiner, B. (2005). How to write job descriptions effectively. Journal of Management Research News, 28(8), 48-54.

HR Guide, (2012). Job analysis and evaluation method. Retrieved from http: //www.hrguide.com/data/goo.htm

Inyang, B. J. \& Akpama, A. M. (2002). Personnel management practice in Nigeria. Calabar: Merb Business Publisher.

Kshatriya, S. (2016). Linkage of job analysis to performance management: A case study. International Journal of Management Information Technology and Engineering, 6(9), 202-222.

Kshatriya, S. (2016). Job analysis and its positive impact on key recruitment and selection processes: A case study. Al Dar Research Journal of Sustainability, 1(1), 47-68.

McCormick, E. J. (1979). Job analysis: Methods and applications. New York: Amacom.

Mclagan, P. (1997). Competencies: The next generation. The Journal of Training and Development, 51(5), 40-47.

Meade, J. (1998). Identifying criteria for success helps in making effective hiring decisions. Human Resource Magazine, 43(5), 49-50.

Mozdabadi, S. M. T. (2016). Investigation of educational needs with job analysis approach (case study: Financial and urban economy experts of Tehran Municipality). The Scientific Research Quarterly Journal of Urban Economics and Management, 4(3), 127-146.

Musyoka, F. N., Adoya, M. A. \& Ongombe, M. O. (2016). Influence of job description on performance of health workers in public hospitals: A case of Mbagathi Hospital Nairobi city country. Science Journal of Public health, 4(2), 88-93.

Nolan, P. (1998). Competencies drive decision making. Journal of Nursing Management, 29(3), 23-29.

Nyasha, M., Katsuro, P., Chazuza, T., Makaita, M. M., Mukondiwa, T., Farai, M., Kudakwashe, N. N., Tafadzwa, U. \& Taongo, M. (2013). Importance of establishing a job analysis exercise in an organization: A case study of bread manufacturing companies in Zimbabwe. Austrian Journal of Business and Management Research, 2(11), 35-42.

Oswald, F. L. (2003). Job analysis: Methods, research, and applications for human resource management in the new millennium. Journal of Personnel Psychology, 56(3), 798-802.

Raju, K. K. \& Banerjee, S. (2017). A study on job description and its effect on employee performance. Case of some selected manufacturing organizations in the city of Pune, India. International Journal of Latest Technology in Engineering, Management \& Applied Science (IJLTEMAS), 6(2) 1-10. 
Rehman, S. M. (2009). Impact of job analysis on job performance: A case study of public sector organizations of Pakistan. Ph.D. Thesis of National University of Modern Languages Islamabad. Retrieved on 25/06/2012 www.eprints.hec.gov.pk/6512/

Saif, N., Khan, M. S. Rehman, Shafiq-Ur, R., Zia-Ur, R., Nawa, T. \& Naqeeb, M. (2013). Competency based job analysis. International Journal of Academic Research in Accounting, Finance and Management, 3(1), 105-111.

Sharif, A. \& Karim, M. M. (2017). Influence of job analysis program on employees: A study of selected companies of Bangladesh. International Journal of Scientific \& Engineering Research, 8(5), 1221-1225.

Siddique, C. M. (2004). Job analysis: Strategic human resource management practice. International Journal of Human Resource Management, 15(1), 219-244.

Singh, P. S. (2008). Job analysis for a changing workplace. Journal of Applied Psychology, 88(4), 635-646.

Singh, P. S. (2010). Human resource management $\left(1^{\text {st }}\right.$ ed). India: Virender Kumar Arya Publisher.

Stybel, L. J. (2010). Managing the inner contradictions of job descriptions: A technique for use in recruitment. The Psychologist-Manager Journal, 13(1), 105-110.

Stoilkovska, A. Serafimovic, G. (2017). Job analysis as an important human resource management function. International Refereed Scientific Journal Vision, 2(1), 113-124.

Suthar, B. K., Chakravarthi, T. L. \& Pradhan, S. (2014). Impacts of job analysis on organizational performance: An inquiry on Indian public sector enterprises. ELSEVIER Procedia Economics and Finance, 11, 166-181.

Weihrich, H. \& Koontz, H. (2005). Management: A global perspective (11 ${ }^{\text {th }}$ Ed). New Delhi: Tata McGraw -Hill Publishing Company.

Wikipedia (2019). Job analysis and its methods. Retrieved from www.wikipedia.org/w/index.php 